\title{
Role of Interim PET Scan after 2 Cycles of ABVD in Pediatric Hodgkin Lymphoma: Retrospective Multicenter Study from South India
}

\author{
Arun Seshachalam ${ }^{1}$ Shashidhar V. Karpurmath ${ }^{2, *}$ Krishnakumar Rathnam ${ }^{3, *}$ Arathi Srinivasan ${ }^{4}$ \\ Julius Scott ${ }^{5}$ Raman S. G. ${ }^{6} \quad$ M. Janarthinakani ${ }^{6} \quad$ Krishna Prasad $^{7}$ Channappa Patil $^{8}$ \\ Parameswaran Anoop ${ }^{8}$ Neelesh Reddy ${ }^{9}$ Satish Kumar Anumula ${ }^{9}$ Sirigeri Prabhakar Roopa ${ }^{9}$ \\ Krishna Reddy Golamari ${ }^{10}$ Madhav Danthala ${ }^{10}$ Basawantrao Malipatil ${ }^{9}$ Bharath Rangarajan ${ }^{11}$ \\ Karthik S. Udupa ${ }^{12}$ Manjunath Nandennavar ${ }^{2}$ Kesavan Niraimathi ${ }^{13}$
}

${ }^{1}$ Dr. GVN Cancer Institute, Tiruchirappalli, Tamil Nadu, India

${ }^{2}$ Vydehi Institute of Medical Sciences and Research Centre, Bengaluru, Karnataka, India

${ }^{3}$ Meenakshi Mission Hospital and Research Center, Madurai, Tamil Nadu, India

${ }^{4}$ Kanchi Kamakoti CHILDS Trust Hospital, Nungambakkam, Chennai, Tamil Nadu, India

${ }^{5}$ Sri Ramachandra Medical Center, Porur, Chennai, Tamil Nadu, India

${ }^{6}$ Madras Cancer Care Foundation, Chennai, Tamil Nadu, India

${ }^{7}$ Mangalore Institute of Oncology, Mangaluru, Karnataka, India

${ }^{8}$ Apollo Hospital, Bengaluru, Karnataka, India
Address for correspondence Arun Seshachalam, MD, DM, Department of Medical Oncology, Dr GVN Cancer Institute, 46, near Super Bazzar, Singarathoppe, Tiruchirappalli, Tamil Nadu, 620008, India (e-mail: arunonco@gmail.com).

\footnotetext{
${ }^{9}$ Columbia Asia Hospital, Bengaluru, Karnataka, India

${ }^{10}$ Manipal Hospital, Vijayawada, Andhra Pradesh, India

11 Kovai Medical Center and Hospital, Coimbatore, Tamil Nadu, India

12 Kasturba Medical College, Manipal, Karnataka, India

${ }^{13}$ Fenivi Research Solutions, Chennai, Tamil Nadu, India
}

Ind J Med Paediatr Oncol 2021;42:415-425.
Abstract
Keywords
- iPET2
- pediatric Hodgkin lymphoma
- prognosis
- relapse
- CMOG

Introduction Most Indian centers use Adriamycin/Bleomycin/Vinblastine/Dacarbazine (ABVD) chemotherapy for pediatric Hodgkin lymphoma $(\mathrm{pHL})$. To reduce the late toxicity, robust predictive markers are needed to risk stratify $\mathrm{pHL}$ patients, thereby limiting the number of chemotherapy cycles and omitting radiation for low-risk and intensifying treatment for high-risk children.

Objective This study was conducted to analyze the outcome of $\mathrm{pHL}$ patients treated with ABVD and various factors predicting the outcome.

Materials and Methods This retrospective study analyzed the outcome of 113 consecutive $\mathrm{pHL}$ children treated with ABVD chemotherapy from 11 tertiary care centers in South India from 2009 to 2019.

Results The median duration of follow-up was 2.73 years. The median age was 13 years. B symptoms are seen in $50.5 \%$ patients, bulky disease in $23 \%$, and stage IV in $28.3 \%$. Of $113 \mathrm{pHL}, 69 \%$ had a positron emission tomography (PET) and $31 \%$ had computed tomography (CT)-based staging. Stage IV (37.1\%) and extranodal involvement (31.2\%) were seen more often with PET than with CT staging (8.5 and $2.8 \%$,

Both authors contributed equally to the manuscript.

DOI https://doi.org/ 10.1055/s-0041-1730240. ISSN 0971-5851. (c) 2021. Indian Society of Medical and Paediatric Oncology. All rights reserved.

This is an open access article published by Thieme under the terms of the Creative Commons Attribution-NonDerivative-NonCommercial-License, permitting copying and reproduction so long as the original work is given appropriate credit. Contents may not be used for commercial purposes, or adapted, remixed, transformed or built upon. (https://creativecommons.org/ licenses/by-nc-nd/4.0/)

Thieme Medical and Scientific Publishers Pvt. Ltd., A-12, 2nd Floor, Sector 2, Noida-201301 UP, India 
respectively). Among 64 patients with interim PET scan after two cycles (iPET2), 20.3\% did not achieve complete remission (CR) and no factors were significantly associated. The 4-year event-free survival (EFS) rate of the entire cohort was $86 \%$. The 4-year EFS rate was $93 \%$ for patients with CR in iPET2 and $52 \%$ for patients not achieving $C R$. The only independent predictor of low EFS was iPET2 response $(p<0.05)$.

Conclusion Our study confirms the prognostic role of PET scan staging and response assessment. Not achieving CR on the iPET2 scan indicates poor prognosis and warrants clinical trial enrollment for a better outcome.

\section{Introduction}

The cure rate of pediatric Hodgkin lymphoma (pHL) with combined multiagent-chemotherapy and radiation has steadily improved over the years. ${ }^{1-12}$ The primary aim of combined modality treatment in pHL is to strike a balance between cure and late toxicity. Consequently, efforts have focused on risk-based and response-based strategies. The German society of Pediatric Oncology and HematologyHodgkin diseases 95 trial showed radiation therapy (RT) could be safely omitted in low-risk pHL. ${ }^{13}$ The European pediatric and adolescent HL network evaluated the omission of RT in all patients with adequate positron emission tomography (PET)-based response to two cycles of Oncovin/Etoposide/Prednisone/Adriamycin (OEPA). The interim results of this study suggested the feasibility of eliminating RT in patients with an adequate response. The use of OEPA/COPDAC in pHL patients decreases the total cumulative dose of alkylators and anthracyclines, but the long-term toxicity associated with etoposide, procarbazine, and radiation needs consideration. ${ }^{14}$

In a resource-limited setting, factors like management cost, treatment abandonment, availability of pediatric oncologist, and lack of transplant centers play a key role in the outcome. As the number of relapsed pHL undergoing salvage chemotherapy and the transplant is low, most of the centers in India aim for a high cure rate with low relapses and continue to use Adriamycin/Bleomycin/Vinblastine/Dacarbazine (ABVD) chemotherapy. ${ }^{15-19}$ To reduce the late toxicity and limit to the number of chemotherapy cycles, we need to identify robust predictive markers that risk stratifies $\mathrm{pHL}$ patients into low-risk and high-risk categories.

Although the International Prognostic Score (IPS) is widely used for prognostication of $\mathrm{HL}$, it includes certain predictors that are not applicable to the pediatric/adolescent population. ${ }^{20-23}$ Role of Childhood Hodgkin International Prognostic Score (CHIP) is limited to intermediaterisk pHL patients and there is a paucity of data regarding the prognostic role of CHIP in pHL patients treated with ABVD. ${ }^{24,25}$

The present data on the role of iPET2 scan in pHL patients are conflicting and require further prospective trials. ${ }^{26-30}$ In comparison with adult HL patients, the studies on interim PET scan after two cycles (iPET2) response adapted treatment modification in children are sparse. ${ }^{26,31-34}$
This study was conducted to ascertain the outcomes of children with HL treated with ABVD chemotherapy and to analyze various factors predicting the outcome.

\section{Materials and Methods}

\section{Study Design}

Ours was a retrospective study with secondary data collection.

\section{Patient Eligibility}

One hundred and thirteen consecutive HL patients, younger than or equal to 18 years of age, and started on the ABVD chemotherapy regimen were included. Patients who were diagnosed, but refused treatment, were excluded. Patients diagnosed as nodular lymphocytes preponderance HL were excluded.

\section{Study Period and Study Sites}

We collected the data of all consecutive, previously untreated pHL patients from February 1, 2009 to January 31, 2019. The study was conducted in 11 private tertiary care centers involving nine cities across three states in South India (-Appendix A).

\section{Diagnosis and Management of pHL}

All patients required histopathological diagnosis using excisional nodal or core needle or bone marrow biopsy. Morphologic evaluation and classification of the patients were done by the revised World Health Organization (WHO) Classification of Tumours of Hematopoietic and Lymphoid Tissues. ${ }^{35}$

The workup included documentation of presenting complaints including B symptoms (unexplained fevers, more than $10 \%$ weight loss and/or drenching night sweats), physical examination, and investigation reports. The stage was assigned based on The Ann Arbor staging system with Cotswolds modifications and decided using clinical examination, computed tomography (CT), and/or PET scan. ${ }^{36}$ Earlystage prognostic grouping included stage $\mathrm{I}_{\mathrm{A}}, \mathrm{II}_{\mathrm{A}}, \mathrm{I}_{\mathrm{X}}, \mathrm{II}_{\mathrm{X}}$, and advanced stage included stage $\mathrm{I}_{B}, \mathrm{II}_{\mathrm{B}}$, III, and IV. Early-stage pHL patients were further categorized into favorable and unfavorable based on the presence of one or more risk factors. The risk factors were extranodal disease, bulky mediastinum, erythrocyte sedimentation rate (ESR) more than $50 \mathrm{~mm} / \mathrm{h}$, and three or more nodal site involvement. 
The chemotherapy regimens used to treat the patients during the study period were ABVD. The risk stratification, number of cycles of chemotherapy, the timing of response assessment, the addition of involved-field radiotherapy (IFRT), and the IFRT dose were individualized based on the decision of the treating institution multidisciplinary tumor board. Patients with early-stage disease (stages I and II) and advanced-stage disease (stages III and IV) were scheduled for a minimum of four and six cycles of chemotherapy respectively. The response was assessed clinically after each cycle and radiologically after completion of two cycles for earlystage and after two or four cycles of chemotherapy for advanced-stage pHL patients. Few patients had the radiologic assessment of response after completing six cycles. It was the practice during the period of study in some treating centers to restrict to two cycles of chemotherapy along with IFRT for early-stage-favorable pHL patients and to give two additional cycles of chemotherapy after documentation of radiologic complete remission (CR) for a maximum of six cycles for early-stage and eight cycles in advanced-stage $\mathrm{pHL}$ patients.

ABVD was delivered as per the original schedule. ${ }^{37,38}$ Interim response assessment was done after two cycles for early-stage and two or four cycles for the advanced stage. Radiology reporting of the interim CT scans was based on Lugano recommendation for response assessment and PET images according to the five-point Deauville score. ${ }^{39,40}$ Deauville score of one, two, or three were considered as negative/(CR) in interim scans, while a score of one and two was considered negative/CR at end of treatment scans. Repeat imaging (PET or CT) was done after the completion of additional chemotherapy cycles.

Patients who failed to achieve CR after two cycles of ABVD, bulky disease at presentation, early-stage patients, and residual disease at the end of treatment were considered for consolidation radiotherapy. In patients who initially had bulky disease, early-stage patients received IFRT with a total dose of between 20 and $30 \mathrm{~Gy}$, and in patients with residual disease, IFRT was administered to the site at a dose that was between 30 and 36 Gy. IFRT was administered in a daily fraction of 1.8 to $2 \mathrm{~Gy}$ and was given 5 days of the week.

After completing treatment, patients were followed up clinically and investigations were performed only if there were clinical signs or symptoms.

\section{HL Electronic Database}

As a routine, a list of all newly registered patients with $\mathrm{HL}$ was prepared based on the information collected using a data collection form (-Appendix B) from patient case records, outpatient department files, and investigation reports. This was retrospectively captured into an electronic database using online Google forms in all the 11 tertiary care centers.

\section{Data Variables and Source of Data}

Variables extracted from the pHL electronic database were the name of the treating center, patient ID, age, stage, sex, B symptoms, site of lymphadenopathy, albumin, ESR, histology, extranodal sites, mediastinal involvement, interim and end of treatment response, treatment toxicity, treatment modifications, and outcome (alive and in remission, relapse, death, loss to follow-up). CHIP score was calculated using four variables (fever, hypoalbuminemia, mediastinal involvement, and stage IV). Dates of diagnosis, treatment initiation of ABVD, iPET scan, and outcome or censoring (whichever was earlier) were also collected. The loss to follow-up was defined as "missing two scheduled visits to the center and not responding to telephonic reminders." The last center visit was considered as the date of loss to follow-up. Patients who were lost to follow-up were censored and not considered for analysis after the date of loss to follow-up.

\section{Data Analysis}

Data were analyzed using STATA (version 12.1, copyright 1985-2011 StataCorp LP USA, serial number: 30120504773). Frequency, proportion, mean (standard deviation [SD]), median (interquartile range [IQR]) were used.

Our primary objective was to measure the event-free survival (EFS)and overall survival (OS) at 2 years and 5 years. Any relapse, death, or treatment failure was considered as an "event" (unfavorable outcome). Not achieving CR at the end of treatment with ABVD chemotherapy was considered a treatment failure. Since only one death was documented, OS was not calculated. All patients were censored at the date of lost to follow-up, or May 31, 2019, whichever was earlier. EFS was estimated using the Kaplan-Meier method, and variables were compared using the log-rank test. $p$-values $<$ 0.05 were considered significant. Crude hazard ratios were calculated using Cox proportional hazard regression to determine the risk factors for events. Factors predicting outcome and nonachievement of CR in an iPET2 scan were assessed using log-binomial regression.

\section{Ethics}

Ethics approval was obtained from Dr. GVN Ethics Committee, Dr. GVN cancer institute, Tiruchirappalli, India (Protocol No. PHL/07/2018 dated July 30, 2018) (-Appendix C). As the study involved the review of patient records (secondary data), a waiver for informed consent was sought and approved by the ethics committees. Administrative approval was obtained from collaborative institutions before starting the study and was performed in accordance with the ethical standards laid down in the 1964 Declaration of Helsinki and its later amendments.

\section{Results}

One hundred and thirteen patients with pHL were identified during the 10 years. The median age was 13 years (SD: 4.96) and 83 of 113 pHL patients (73.5\%) were male. The most common histopathology was mixed cellularity (32.8\%) (-Table 1).

\section{Baseline Imaging Characteristics}

Of 113 pHL, 78 (69.1\%) patients had PET scan and 35 (30.9\%) had CT scans as baseline investigation. Stage IV disease was 
Table 1 Profile of pHL patients treated in 11 tertiary care centers across South India (2009-2019)

\begin{tabular}{|c|c|}
\hline Characteristics & $n(\%)$ \\
\hline Total & $113(100.0)$ \\
\hline \multicolumn{2}{|l|}{ Demographic } \\
\hline \multicolumn{2}{|l|}{ Age (in y) } \\
\hline$\leq 5$ & $17(15.1)$ \\
\hline $06-12$ & $37(32.7)$ \\
\hline $13-18$ & $59(52.2)$ \\
\hline \multicolumn{2}{|l|}{ Sex } \\
\hline Male & $83(73.5)$ \\
\hline Female & $30(26.5)$ \\
\hline \multicolumn{2}{|l|}{ Clinical } \\
\hline B-symptoms & $57(50.5)$ \\
\hline Bulky disease (nodal size $>6 \mathrm{~cm}$ ) & $26(23.0)$ \\
\hline \multicolumn{2}{|l|}{ Number of nodal sites } \\
\hline$<3$ & $11(9.7)$ \\
\hline$\geq 3$ & $102(90.3)$ \\
\hline \multicolumn{2}{|l|}{ Laboratory } \\
\hline \multicolumn{2}{|l|}{ Histopathology } \\
\hline Nodular sclerosis & $19(16.8)$ \\
\hline Mixed cellularity & $37(32.8)$ \\
\hline Lymphocyte rich & $13(11.6)$ \\
\hline Lymphocyte depleted & $1(0.8)$ \\
\hline Unclassified & $43(38.0)$ \\
\hline \multicolumn{2}{|l|}{$\mathrm{ESR}(\mathrm{mm} / \mathrm{h})$} \\
\hline$<30$ & $25(22.2)$ \\
\hline $30-50$ & $14(12.4)$ \\
\hline$>50$ & $24(21.2)$ \\
\hline Not done & $45(39.8)$ \\
\hline Missing data & $5(4.4)$ \\
\hline Albumin $<35 \mathrm{gm} / \mathrm{dL}$ & $35(40.0)$ \\
\hline \multicolumn{2}{|l|}{ Staging investigation results } \\
\hline Mediastinal involvement & $49(43.4)$ \\
\hline Bulky mediastinum & $11(9.7)$ \\
\hline \multicolumn{2}{|l|}{ CHIP score } \\
\hline Low risk $(0-1)$ & $60(53.1)$ \\
\hline High risk $(2,3,4)$ & $53(46.9)$ \\
\hline
\end{tabular}

Abbreviations: CHIP score, Childhood Hodgkin International Prognostic score; ESR, erythrocyte sedimentation rate; $\mathrm{pHL}$, pediatric Hodgkin lymphoma.

seen in $29(37.1 \%)$ of 78 pHL patients with a baseline PET evaluation and three (8.5\%) of $35 \mathrm{pHL}$ patients with a baseline CT scan evaluation. Extranodal sites were seen in 29 (37.1\%) of 78 pHL patients with baseline PET scan evaluation and one (2.8\%) of $35 \mathrm{pHL}$ patients with baseline CT scan evaluation (-Table 2).

\section{Prognostic Grouping and Treatment's Profile}

Stage I was seen in $13(11.5 \%)$ pHL patients and stage IV in 32 (28.3\%) patients (-Table 2). Of 113 patients, 104 patients completed treatment, six patients abandoned treatment, and three had a change of treatment protocol due to progressive disease. The early-stage based on prognostic grouping was seen in 34 (30.0\%) and advanced stage in 79 (69.9\%) patients (-Table 3 ).

\section{Early-Stage Disease}

Of 34 early-stage pHL patients, six (17.6\%) were in favorable and $28(82.4 \%)$ were in unfavorable prognostic group (-Table 3). The median number of cycles of ABVD chemotherapy in early-stage pHL patients was four cycles (range: 2 , 8 ). Three of the six favorable prognostic group early-stage pHL patients received two cycles along with IFRT treatment. Fifteen (44.1\%) early-stage patients received four cycles, of which six underwent combined modality treatment (-Table 4).

\section{Advanced Stage}

Of 79 advanced-stage pHL patients, 42 (53.1\%) received six cycles and $28(35.4 \%)$ received eight cycles ABVD chemotherapy ( - Table 4 ). The median number of cycles was six (range: $2,8)$. Nine advanced pHL patients discontinued ABVD treatment. Among nine patients, five patients are alive and disease-free, two patients are alive with the disease on metronomic treatment, one patient died due to progressive disease, and one patient with the progressive disease was rescued with salvage chemotherapy followed by transplant. Radiotherapy was given to 15 (18.9\%) out of 79 advanced pHL patients, of which six cases received RT for partial remission status in the interim scan, six cases for the bulky site at initial presentation, and three cases for the residual disease at the end of treatment.

\section{Response Assessment}

Results of the interim and end of treatment assessment are depicted in - Table 5. CR at interim and end of treatment assessment was $79.4 \%(n=69)$ and $87.7 \%(n=57)$ with PET and $46.1(n=12)$ and $77.5 \%(n=31)$ with CT-based imaging, respectively. Nearly $92.0 \%$ completed treatment and $85.0 \%$ achieved CR at the end of treatment.

\section{iPET2 Response Assessment}

Among 113 patients, 64 (56.6\%) patients underwent iPET2 scan. - Fig. 1 depicts the outcome of pHL children with iPET2 scans. Of the 64 children with iPET2 scan, 51 (79.7\%) patients achieved $C R$, and $13(20.3 \%$ ) failed to achieve CR.

Five of 64 patients with iPET2 scan discontinued treatment. Among those five patients, four are alive and diseasefree and one patient had treatment failure. Of the four patients who are alive and disease-free, three patients had CR in iPET2 scan and one had progressive disease in iPET2 requiring salvage chemotherapy and transplant. The patient who had treatment failure did not achieve CR in the iPET2 scan. 
Table 2 Staging outcomes based on the baseline imaging used for initial evaluation of pHL patients treated in 11 primary centers across South India (2009-2019)

\begin{tabular}{|l|l|l|l|}
\hline Parameters & $\begin{array}{l}\text { Total } \\
\boldsymbol{n}(\%)\end{array}$ & $\begin{array}{l}\text { PET based } \\
\boldsymbol{n}(\%)\end{array}$ & $\begin{array}{l}\text { CT based } \\
\boldsymbol{n}(\%)\end{array}$ \\
\hline Total & $113(100)$ & $78(100)$ & $35(100)$ \\
\hline Stage & & & \\
\hline Stage I & $13(11.5)$ & $12(15.4)$ & $1(2.8)$ \\
\hline Stage II & $38(33.6)$ & $21(27.0)$ & $17(48.5)$ \\
\hline Stage III & $30(26.6)$ & $16(20.5)$ & $14(40.0)$ \\
\hline Stage IV & $32(28.3)$ & $29(37.1)$ & $3(8.5)$ \\
\hline Extranodal involvement & & & \\
\hline Spleen & $12(10.6)$ & $12(15.4)$ & - \\
\hline Bone & $14(12.3)$ & $14(17.9)$ & - \\
\hline Others ${ }^{\text {a }}$ & $7(6.2)$ & $6(7.7)$ & $1(2.8)$ \\
\hline Mediastinum involvement & $49(43.4)$ & $34(43.6)$ & $15(42.8)$ \\
\hline Bulky sites involvement & $26(23.0)$ & $16(20.5)$ & $10(28.5)$ \\
\hline
\end{tabular}

Abbreviations: $\mathrm{CT}$, computed tomography; PET, positron emission tomography; pHL, pediatric Hodgkin lymphoma.

aLung-5, liver-1, skin-1 (1 case had both lung and spleen involvement, 1 case had both lung and skin involvement, and 1 case had bone and spleen).

Table 3 Staging and prognostic grouping of $\mathrm{pHL}$ patients treated in 11 tertiary care centers across South India (20092019)

\begin{tabular}{|l|l|}
\hline Characteristics & $\boldsymbol{n}(\%)$ \\
\hline Stage & \\
\hline I & $13(11.5)$ \\
\hline II & $38(33.6)$ \\
\hline III & $30(26.6)$ \\
\hline IV & $32(28.3)$ \\
\hline Early stage $^{\mathrm{a}}$ & $34(30.0)$ \\
\hline Favorable $^{\mathrm{b}}$ & $6 / 34(17.6)$ \\
\hline Unfavorable $^{\mathrm{b}}$ & $28 / 34(82.4)$ \\
\hline Advanced stage $^{\mathrm{c}}$ & $79(70.0)$ \\
\hline
\end{tabular}

Abbreviation: $\mathrm{pHL}$, pediatric Hodgkin lymphoma.

${ }^{\mathrm{a}} \mathrm{IA}, \mathrm{IIA}, \mathrm{IX}$, and IIX.

${ }^{b}$ Categorized into favorable and unfavorable based on the presence of $\geq$

1 of the following factors: Extranodal disease, bulky mediastinum, ESR

$>50 \mathrm{~mm} / \mathrm{h}, 2$ or more the 2 nodal site involvement.

CIB, IIB, III, and IV.

\section{Toxicity}

The most common acute toxicity was grade IV febrile neutropenia seen in eight patients. There were no cases with anthracycline cardiotoxicity, bleomycin-induced lung toxicity, and second malignancy.

\section{Event Free Survival}

Of the total 337.86 person-years of follow-up, 17 events were documented giving an incidence rate of five (confidence interval $[\mathrm{CI}]$ : 3.1-8.1) per 100 person-years followup. Of 17 events, four had treatment failure, seven relapsed, and six had progressive disease. One patient with a progressive disease died. - Fig. 2 shows the outcome of the entire cohort.

The median duration of follow-up was 2.73 years (IQR: 3.32 years) and the 2- and 4-year EFS of the entire cohort were 86.0 and $81.0 \%$, respectively (-Fig. 3). For early-stage pHL patients, 2- and 4-year EFS rates were 90.0 and $83.0 \%$, while for advanced-stage pHL patients, these were 85.0 and $80.0 \%$, respectively. The 2- and 4-year EFS rates for iPET2 positive patients were 67.0 and $52.0 \%$, while for iPET2 negative patients these were 93.0 and $93.0 \%$, respectively. Of all the factors analyzed, the only independent predictor of low EFS was iPET2 response (-Table 6 ). The survival curves stratified by iPET2 responses are depicted in - Fig. $\mathbf{4}$. When compared with patients with CR on iPET2, patients with incomplete remission (hazard ratio: 5.30 95.0\% [CI]: 1.2522.38) had significantly lower survival. None of the baseline factors predicted the response in iPET2 scans (data not shown).

\section{Discussion}

Our study documents the role of an iPET2 scan in pHL patients and the largest multicenter study from South India to provide insight into demographic profiles, treatment, and outcome of $\mathrm{pHL}$ patients. The main limitation of our study is its retrospective nature and only three-fifths of the entire cohort underwent an iPET2 scan for response assessment. Since formal testing for chemotherapy-related late effects was not done at the study sites, treatment-related late toxicity could not be captured in our study.

The baseline disease characteristics showed a lower median age at presentation, male preponderance, mixed cellularity as commonest histological presentation, increased proportion with B symptoms, and advanced stage at 
Table 4 Treatment profile of pHL patients treated in 11 tertiary care centers across South India (2009-2019)

\begin{tabular}{|l|l|l|}
\hline $\begin{array}{l}\text { Characteristics } \\
\boldsymbol{n}(\%)\end{array}$ & $\begin{array}{l}\text { Total } \\
\boldsymbol{n}(\%)\end{array}$ & $\begin{array}{l}\text { Early stage } \\
\boldsymbol{n}(\%)\end{array}$ \\
\hline Total & $113(100)$ & $34(100)$ \\
\hline Number of ABVD cycles & & $79(100)$ \\
\hline 2 ABVD & - & $3(8.8)$ \\
\hline 4 ABVD & - & $15(44.1)$ \\
\hline 6 ABVD & - & $15(44.1)$ \\
\hline 8 ABVD & - & $1(3.0)$ \\
\hline Combined modality treatment & $24(21.2)$ & $9(11.3)$ \\
\hline
\end{tabular}

Abbreviations: ABVD, Adriamycin/Bleomycin/Vinblastine/Dacarbazine; pHL, pediatric Hodgkin lymphoma.

Table 5 Response assessment of pHL patients treated in 11 tertiary care centers across South India (2009-2019)

\begin{tabular}{|c|c|c|c|c|c|}
\hline Response & Total & $\begin{array}{l}\text { CR } \\
n(\%)\end{array}$ & $\begin{array}{l}\mathrm{PR}^{\mathrm{a}} \\
n(\%)\end{array}$ & $\begin{array}{l}S^{a} \\
n(\%)\end{array}$ & $\begin{array}{l}\mathrm{PD}^{\mathrm{a}} \\
n(\%)\end{array}$ \\
\hline \multicolumn{6}{|l|}{ IR response } \\
\hline Total & 113 & $81(71.7)$ & $28(24.8)$ & $1(0.8)$ & $3(2.7)$ \\
\hline PET based & 87 & $69(79.4)$ & $17(19.5)$ & - & $1(1.1)$ \\
\hline CT based & 26 & $12(46.1)$ & $11(42.4)$ & $1(3.8)$ & $2(7.7)$ \\
\hline \multicolumn{6}{|l|}{ EOT response } \\
\hline Total & $105^{\mathrm{b}}$ & $88(83.8)$ & $11(10.5)$ & $2(1.9)$ & $4(3.8)$ \\
\hline PET based & 65 & $57(87.7)$ & $6(9.2)$ & - & $2(3.1)$ \\
\hline CT based & 40 & $31(77.5)$ & $5(12.5)$ & $2(5.0)$ & $2(5.0)$ \\
\hline
\end{tabular}

Abbreviations: $\mathrm{CR}$, complete remission; $\mathrm{CT}$, computed tomography; EOT, end of treatment; IR, interim response; PD, progressive disease; PET, positron emission tomography; $\mathrm{pHL}$, pediatric Hodgkin lymphoma; PR, partial remission; SD, stable disease.

${ }^{a}$ Number in the parentheses denotes row percentage.

${ }^{\mathrm{b}}$ Eight patients missed end of treatment assessment.

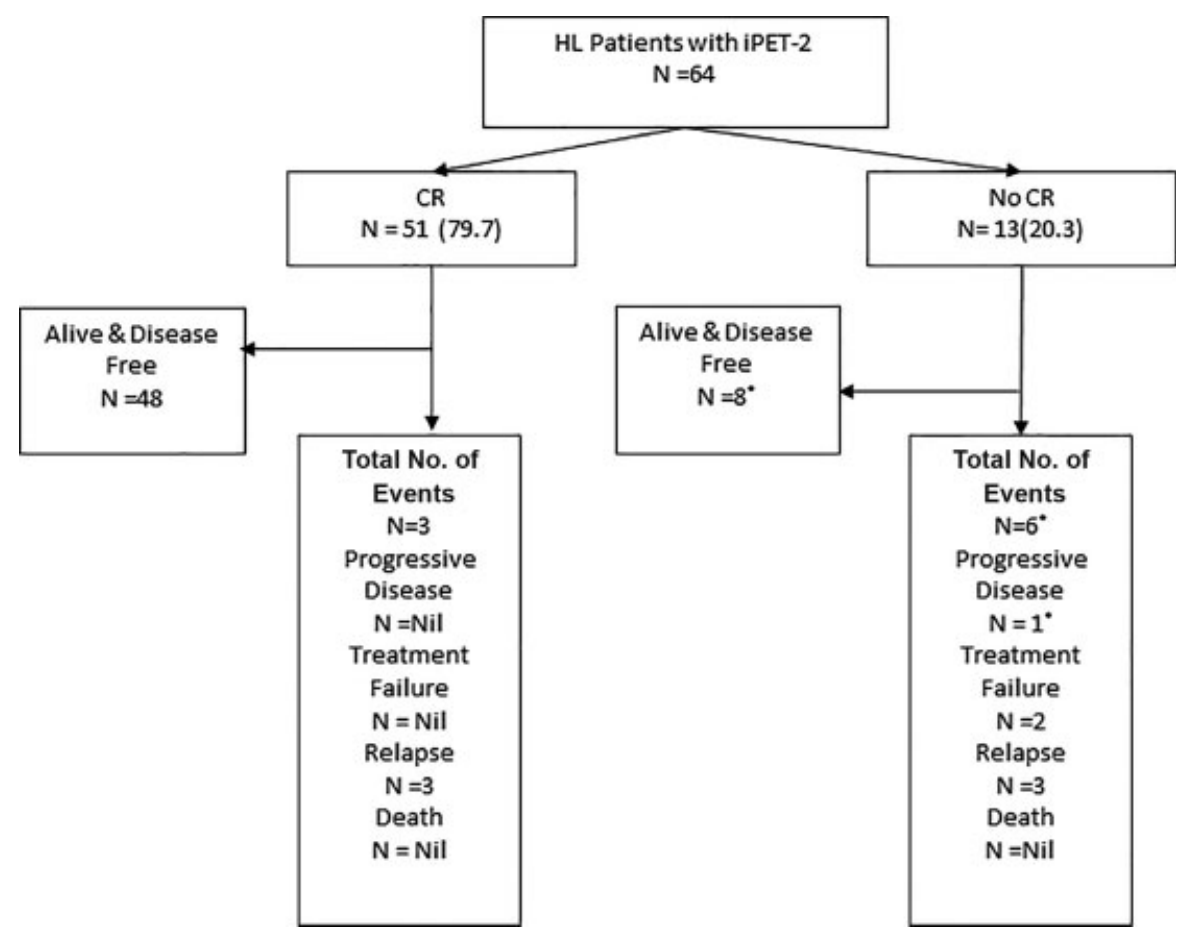

Fig. 1 Flowchart depicting the outcome of pHL patients with iPET2 scan treated in 11 primary centers across South India (2009-2019). Abbreviations: CHIP, Childhood Hodgkin International Prognostic; PHL, pediatric Hodgkin lymphoma; iPET2, interim PET scan after two cycles; CR, complete response. *One patient with progressive disease in PET2 underwent salvage chemotherapy and transplant following which he is alive and disease free. 


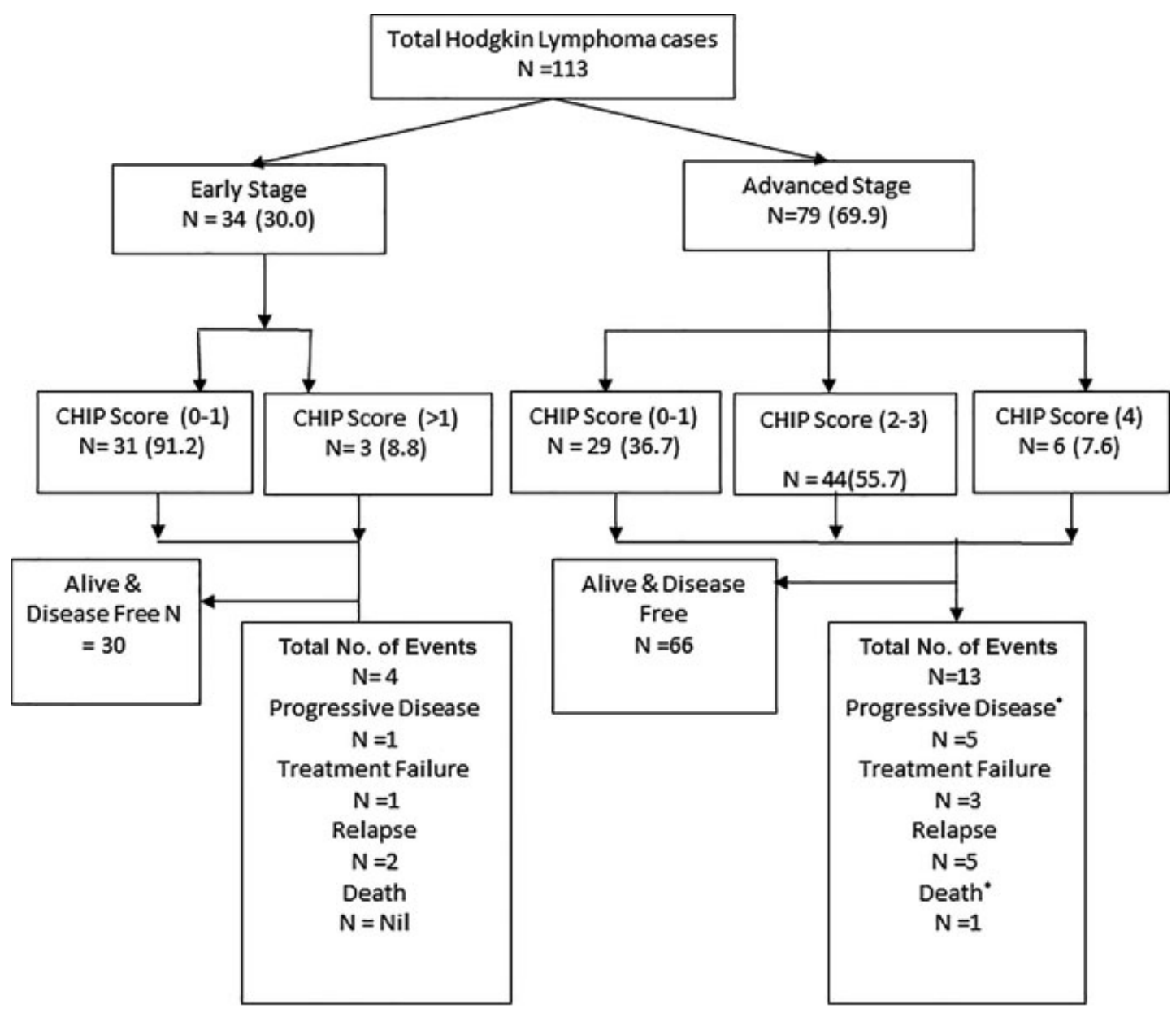

Fig. 2 Flowchart depicting the outcome of all pHL patients treated in 11 primary centers across South India (2009-2019).

Abbreviation: pHL, pediatric Hodgkin lymphoma. ${ }^{*}$ One patient died due to progressive disease, so the event is taken as a progressive disease for analysis.

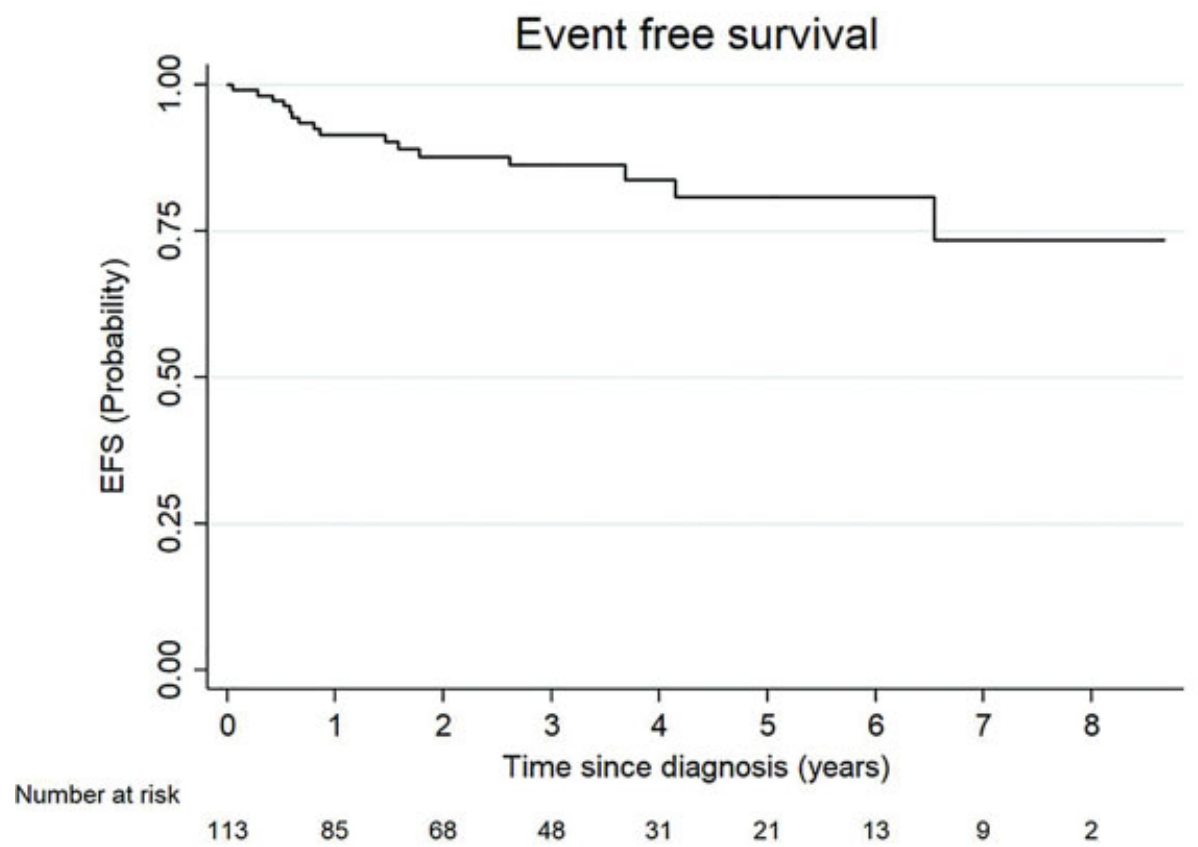

Fig. 3 Event-free survival of pHL patients treated in 11 primary centers across South India (2009-2019): $(n=113)$. pHL, pediatric Hodgkin lymphoma. 
422 Role of iPET2 Scan in Pediatric Hodgkin Lymphoma Seshachalam et al.

Table 6 Association of factors (unadjusted analysis) with event-free survival of pHL patients treated in 11 tertiary care centers across South India (2009-2019)

\begin{tabular}{|c|c|c|c|c|}
\hline \multicolumn{2}{|l|}{ Parameters } & \multirow{2}{*}{$\begin{array}{l}\text { Hazard ratio } \\
\text { Reference }\end{array}$} & \multirow[t]{2}{*}{$\mathrm{Cl}$} & \multirow[t]{2}{*}{$p$-Value } \\
\hline Sex & Male & & & \\
\hline & Female & 1.154 & $0.403-3.308$ & 0.790 \\
\hline \multirow[t]{2}{*}{ B-symptoms } & Absent & 0.619 & $0.233-1.644$ & 0.336 \\
\hline & Present & Reference & & \\
\hline \multirow[t]{4}{*}{ Stage } & 1 & 0.676 & $0.075-6.078$ & 0.727 \\
\hline & II & 0.993 & $0.266-3.702$ & 0.992 \\
\hline & III & 1.604 & $0.467-5.507$ & 0.453 \\
\hline & IV & Reference & & \\
\hline \multirow[t]{2}{*}{ Bulky mediastinum } & Yes & Reference & & \\
\hline & No & 0.776 & $0.273-2.209$ & 0.635 \\
\hline \multirow[t]{2}{*}{ Extranodal present } & Yes & Reference & & \\
\hline & No & 1.077 & $0.347-3.343$ & 0.898 \\
\hline \multirow[t]{2}{*}{ Mediastinum involvement } & Yes & Reference & & \\
\hline & No & 0.999 & $0.385-2.596$ & 0.999 \\
\hline \multirow[t]{2}{*}{$\mathrm{HB}<10.5 \mathrm{gm} / \mathrm{dL}$} & Yes & Reference & & \\
\hline & No & 1.214 & $0.440-3.351$ & 0.708 \\
\hline \multirow[t]{2}{*}{ CHIP score } & Low risk & 1.627 & $0.590-4.486$ & 0.347 \\
\hline & High risk & Reference & & \\
\hline \multirow[t]{2}{*}{ iPET-2 } & No CR & 5.305 & $1.258-22.38$ & 0.023 \\
\hline & CR & Reference & & \\
\hline \multirow[t]{2}{*}{ Radiation } & Given & 0.831 & $0.086-8.004$ & 0.831 \\
\hline & Not given & Reference & & \\
\hline
\end{tabular}

Abbreviations: CHIP score, Childhood Hodgkin International Prognostic score; Cl, confidence interval; CR, complete response; iPET2, interim PET scan after two cycles; NS, not significant; pHL, pediatric Hodgkin lymphoma.

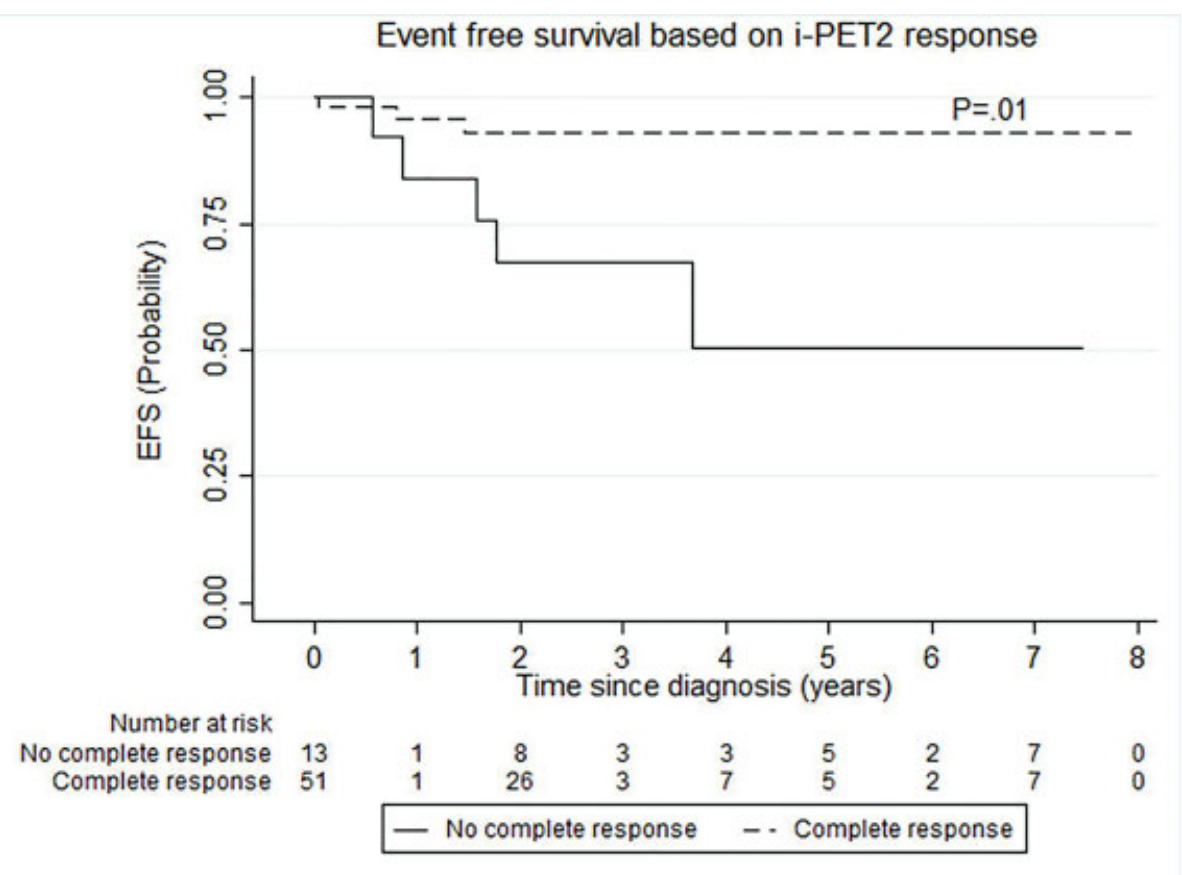

Fig. 4 Event-free survival of pHL patients treated in 11 primary centers across South India (2009-2019): Stratified by interim positron emission tomography scan after two cycles of first-line therapy (iPET2). iPET2, interim positron emission tomography 2; pHL, pediatric Hodgkin lymphoma. 
presentation. Similar findings were reported in previous studies from India. ${ }^{15-19,41,42}$

In our study, one-half of patients had B symptoms, a quarter of patients presented with bulky disease, and two-third was diagnosed with advanced-stage disease. Similar findings were reported in other Indian studies. ${ }^{16,19,35,36,41,43-46}$

Three-fourth of the patients underwent PET scan as an initial staging investigation and one-fourth had CT scan. We noticed more stage IV and extranodal involvement with PET-based imaging. Increased sensitivity and specificity of PET scan in comparison to CT scan-based staging are well reported in the literature. ${ }^{28,47-50}$ However, considering the extensive patient preparation, long examination time, increased cost, and limited availability of PET scan, it is very important to identify the impact of PETbased upstaging on the treatment protocol and long-term outcome.

Treatment offered to our patients was heterogeneous due to the evolution of pHL management over the years and the multicentric nature of our study. Nearly $92.0 \%$ of the study population completed treatment and $83.8 \%$ achieved CR at the end of treatment. Similar CR rates with ABVD were reported from other centers. ${ }^{29,41,42}$ A combined modality approach was used in one-fourth of early-stage patients and one-fifth of advanced-stage patients. The primary aim of combined modality treatment in pHL is to strike a balance between cure and late toxicity. In a resource-limited setting, factors like management cost, treatment abandonment, availability of a pediatric oncologist, and lack of transplant centers play a key role in the outcome. As the number of relapsed pHL undergoing salvage chemotherapy and transplant is low, most of the Indian centers aim for the high cure rate with low relapses and continue to use ABVD chemotherapy. ${ }^{41,42}$ In our study, one out of the 17 patients with adverse outcome was rescued using salvage chemotherapy and transplant.

Three-fifths of our patients underwent iPET2 scan, of which $20.3 \%$ did not achieve CR. Several studies have reported an iPET2 positive rate between 7.6 and 33.3\%. In our study, none of the patients underwent treatment modification based on the iPET2 response. In comparison with adult HL patients, the studies on iPET2 response adapted treatment modification in pHL are sparse. ${ }^{26,31-34}$

In our study, patients not achieving CR in the iPET2 scan had five times increased risk of an adverse outcome when compared with patients achieving CR. Results from several studies on the role of iPET scan in the management of $\mathrm{pHL}$ are varied and conflicting. A prospective Indian study of the $57 \mathrm{pHL}$ patients by Bakhshi et al from India has suggested posttreatment PET scan rather iPET scan to be a predictor of outcome in pHL patients. ${ }^{27}$ The study concluded iPET2 imaging to have low sensitivity with no significant impact on EFS and OS. However, the study showed iPET2 imaging to have higher specificity for predicting relapse (91.4\%) than $\mathrm{CT}$ imaging $(40.3 \%)(p<0.0001) .{ }^{25}$ A retrospective Indian study of $49 \mathrm{pHL}$ patients on ABVD chemotherapy by Totadri et al has demonstrated the possibility of omit- ting radiation in patients who achieve metabolic remission on iPET2 scan. ${ }^{51}$ A study by Furth et al on iPET2 response assessment demonstrated excellent negative predictive value but a poor positive predictive value (PPV) for relapse. ${ }^{28}$ Another study by Ilivitzki et al showed a higher PPV for the same. ${ }^{30}$ Few retrospective studies have shown high sensitivity of iPET assessment. ${ }^{27,29,31}$ Interim analysis from Euronet-HD showed the feasibility of eliminating RT for patients achieving CR in iPET2 scan after two cycles of OEPA. However, long-term outcome of Euronet-HD study is awaited. ${ }^{14}$ Above-mentioned studies were limited by the small number of subjects, short follow-up, retrospective nature, and lack of uniform assessment criteria. $27-29,52,53$ Prospective large randomized study to assess the role of treatment intensification for pHL patients not achieving CR in iPET2 imaging is the need of the hour.

Children's Oncology Group has identified CHIP score as an effective marker for predicting outcome in pHL patients. ${ }^{24}$ In our study, there is no difference in outcome for CHIP scorebased low-risk and high-risk subgroups. A similar finding was reported by Khedr et al from Cairo, Egypt. ${ }^{25}$ Probably, the role of CHIP score in pHL patients treated with ABVD chemotherapy needs further evaluation.

Our study confirms the prognostic value PET scan for all children with pHL for staging and response assessment. Not achieving CR on the iPET2 scan indicates poor prognosis and warrants clinical trial enrollment for a better outcome.

\section{Funding}

Local investigators had the responsibility of collecting the data and entering into the database. Preexisting local resources were used to collect the required information. Hence, no funding was required for this research project

\section{Conflict of Interest}

None.

\section{Acknowledgments}

The research was based on the data shared by the members of Collaborative Medical Oncology Group (CMOG), India. Joseph Joy, Dr. Hariharan K, and Yogesh Achuthanarayanan provided support in data extraction/analysis.

\section{References}

1 Horning SJ, Williams J, Bartlett NL, et al. Assessment of the Stanford $\mathrm{V}$ regimen and consolidative radiotherapy for bulky and advanced Hodgkin's disease: Eastern Cooperative Oncology Group pilot study E1492. J Clin Oncol 2000;18(05):972-980

2 Radford JA, Rohatiner AZS, Ryder WDJ, et al. ChIVPP/EVA hybrid versus the weekly VAPEC-B regimen for previously untreated Hodgkin's disease. J Clin Oncol 2002;20(13):2988-2994

3 Chisesi T, Federico M, Levis A, et al.Intergruppo Italiano Linfomi. ABVD versus Stanford V versus MEC in unfavourable Hodgkin's lymphoma: results of a randomised trial. Ann Oncol 2002;13 (Suppl 1):102-106

4 Diehl V, Franklin J, Pfreundschuh M, et al. German Hodgkin's Lymphoma Study Group. Standard and increased-dose BEACOPP chemotherapy compared with COPP-ABVD for advanced Hodgkin's disease. N Engl J Med 2003;348(24):2386-2395 
5 Weiner MA, Leventhal B, Brecher ML, et al. Randomized study of intensive MOPP-ABVD with or without low-dose total-nodal radiation therapy in the treatment of stages IIB, IIIA2, IIIB, and IV Hodgkin's disease in pediatric patients: a Pediatric Oncology Group study. J Clin Oncol 1997;15(08):2769-2779

6 Maity A, Goldwein JW, Lange B, D’Angio GJ. Comparison of highdose and low-dose radiation with and without chemotherapy for children with Hodgkin's disease: an analysis of the experience at the Children's Hospital of Philadelphia and the Hospital of the University of Pennsylvania. J Clin Oncol 1992;10(06):929-935

7 Koh E-S, Tran TH, Heydarian M, et al. A comparison of mantle versus involved-field radiotherapy for Hodgkin's lymphoma: reduction in normal tissue dose and second cancer risk. Radiat Oncol 2007;2(01):13. Doi: 10.1186/1748-717X-2-13

8 Brämswig JH, Höornig-Franz I, Riepenhausen M, Schellong G. The challenge of pediatric Hodgkin's disease-where is the balance between cure and long-term toxicity?: A report of the West German multicenter studies DAL-HD-78, DAL-HD-82 and DALHD-85 Leuk Lymphoma 1990;3(03):183-193

9 Schellong G. Treatment of children and adolescents with Hodgkin's disease: the experience of the German-Austrian Paediatric Study Group. Baillieres Clin Haematol 1996;9(03):619-634

10 Schellong G, Hörnig-Franz I, Rath B, et al. [Reducing radiation dosage to 20-30 Gy in combined chemo-/radiotherapy of Hodgkin's disease in childhood. A report of the cooperative DAL-HD-87 therapy study]. Klin Padiatr 1994;206(04):253-262

11 Schellong G, Pötter R, Brämswig J, et al.The German-Austrian Pediatric Hodgkin's Disease Study Group. High cure rates and reduced long-term toxicity in pediatric Hodgkin's disease: the German-Austrian multicenter trial DAL-HD-90. J Clin Oncol 1999; 17(12):3736-3744

12 Donaldson SS, Kaplan HS. Complications of treatment of Hodgkin's disease in children. Cancer Treat Rep 1982;66(04):977-989http://www.ncbi.nlm.nih.gov/pubmed/7074658 Accessed April 152021

13 Mauz-Körholz C, Hasenclever D, Dörffel W, et al. Procarbazinefree OEPA-COPDAC chemotherapy in boys and standard OPPACOPP in girls have comparable effectiveness in pediatric Hodgkin's lymphoma: the GPOH-HD-2002 study. J Clin Oncol 2010;28 (23):3680-3686

14 Ozuah NW, Marcus KJ, LaCasce AS, Billett AL. Excellent outcomes following response-based omission of radiotherapy in children and adolescents with intermediate or high-risk Hodgkin lymphoma. J Pediatr Hematol Oncol 2018;40(06):e338-e342

15 Kapoor G, Advani SH, Dinshaw KA, et al. Treatment results of Hodgkin's disease in Indian children. Pediatr Hematol Oncol 1995;12(06):559-569

16 Arya LS, Dinand V, Thavaraj V, et al. Hodgkin's disease in Indian children: outcome with chemotherapy alone. Pediatr Blood Cancer 2006;46(01):26-34

17 Büyükpamukçu M, Varan A, Akyüz C, et al. The treatment of childhood Hodgkin lymphoma: improved survival in a developing country. Acta Oncol 2009;48(01):44-51

18 Fadoo Z, Belgaumi A, Alam M, Azam I, Naqvi A. Pediatric lymphoma: a 10-year experience at a tertiary care hospital in Pakistan. J Pediatr Hematol Oncol 2010;32(01):e14-e18

19 Trehan A, Singla S, Marwaha RK, Bansal D, Srinivasan R. Hodgkin lymphoma in children: experience in a tertiary care centre in India. J Pediatr Hematol Oncol 2013;35(03):174-179

20 Diefenbach CS, Li H, Hong F, et al. Evaluation of the International Prognostic Score (IPS-7) and a Simpler Prognostic Score (IPS-3) for advanced Hodgkin lymphoma in the modern era. $\mathrm{Br} \mathrm{J}$ Haematol 2015;171(04):530-538

21 Ganesan P, Dhanushkodi M, Ganesan TS, et al. Prognostic utility of the IPS 3 score for predicting outcomes in advanced Hodgkin lymphoma. Clin Lymphoma Myeloma Leuk 2019;19(02):116-122

22 Moccia AA, Donaldson J, Chhanabhai $M$, et al. International Prognostic Score in advanced-stage Hodgkin's lymphoma: al- tered utility in the modern era. J Clin Oncol 2012;30(27): 3383-3388

23 Tartas NE, Zerga M, Santos MI, Alfonso G, Amoroso M. International Prognostic Score (IPS) is not useful in stages I-II Hodgkin's lymphoma (HL) - an experience of the Buenos Aires Leukemia Group (BALG). Blood 2006;108:11http://www.bloodjournal.org/content/108/11/4659?sso-checked=true Accessed April 15, 2021

24 Schwartz CL, Chen L, McCarten K, et al. Childhood Hodgkin International Prognostic Score (CHIPS) predicts event-free survival in Hodgkin lymphoma: a report from the Children's Oncology Group. Pediatr Blood Cancer 2017;64:4. Doi: 10.1002/ pbc.26278

25 Khedr R, Mahfouz S, Fathy H, Shalaby L. Childhood Hodgkin International Prognostic Score (CHIPS) and interim PET can predict event-free survival in Hodgkin lymphoma. Clin Lymphoma Myeloma Leuk 2019;19:S311. Doi: 10.1016/j. clml.2019.07.279

26 Metzger ML, Weinstein HJ, Hudson MM, et al. Association between radiotherapy vs no radiotherapy based on early response to VAMP chemotherapy and survival among children with favorable-risk Hodgkin lymphoma. JAMA 2012;307(24):2609-2616. Doi: 10.1001/jama.2012.5847

27 Bakhshi S, Bhethanabhotla S, Kumar R, et al. Posttreatment $\mathrm{PET} / \mathrm{CT}$ rather than interim PET/CT using Deauville criteria predicts outcome in pediatric Hodgkin lymphoma: a prospective study comparing PET/CT with conventional imaging. J Nucl Med 2017;58(04):577-583

28 Furth C, Steffen IG, Amthauer H, et al. Early and late therapy response assessment with [18F]fluorodeoxyglucose positron emission tomography in pediatric Hodgkin's lymphoma: analysis of a prospective multicenter trial. J Clin Oncol 2009;27(26): 4385-4391

29 Hussein S1, Moustafa H 1, Omar W 2, El-Haddad, A 3. FDG-PET/CT in Early Assessment of Response to Therapy in Pediatric Hodgkin Lymphoma. Egyptian J.Nucl. Med., Vol 72013

30 Ilivitzki A, Radan L, Ben-Arush M. Israel O, Ben-Barak A. Early interim FDG PET/CT prediction of treatment response and prognosis in pediatric Hodgkin disease-added value of low-dose CT. Pediatr Radiol 2013;43(01):86-92

31 Seshachalam A, Karpurmath SV, Rathnam K, et al. Does interim PET scan after 2 cycles of ABVD predict outcome in Hodgkin lymphoma? Real-world evidence. J Glob Oncol 2019;5(05): 1-13

32 Dann EJ, Bairey O, Bar-Shalom R, et al. Modification of initial therapy in early and advanced Hodgkin lymphoma, based on interim PET/CT is beneficial: a prospective multicentre trial of 355 patients. Br J Haematol 2017;178(05): 709-718

33 Ganesan P, Kumar L, Raina V, et al. Hodgkin's lymphoma-longterm outcome: an experience from a tertiary care cancer center in North India. Ann Hematol 2011;90(10):1153-1160

34 Johnson P, Federico M, Kirkwood A, et al. Adapted treatment guided by interim PET-CT scan in advanced Hodgkin's lymphoma. N Engl J Med 2016;374(25):2419-2429

35 WHO Classification of Tumours of Haematopoietic and Lymphoid Tissues. Fourth Edition - WHO - OMS -. http://apps.who.int/bookorders/anglais/detart 1 .jsp? codlan $=1 \& \operatorname{cod}$ col $=70 \& \operatorname{cod} c \mathrm{ch}=4002$. Accessed April 15, 2021

36 Olweny CL. Cotswolds modification of the Ann Arbor staging system for Hodgkin's disease. J Clin Oncol 1990;8(09):1598http:// www.ncbi.nlm.nih.gov/pubmed/2264856 Accessed April 15, 2021

37 Bonadonna G, Zucali R, Monfardini S, De Lena M, Uslenghi C. Combination chemotherapy of Hodgkin's disease with Adriamycin, bleomycin, vinblastine, and imidazole carboxamide versus MOPP. Cancer 1975;36(01):252-259http://www.ncbi.nlm.nih.gov/pubmed/54209 Accessed April 15, 2021 
38 Canellos GP, Anderson JR, Propert KJ, et al. Chemotherapy of advanced Hodgkin's disease with MOPP, ABVD, or MOPP alternating with ABVD. N Engl J Med 1992;327(21):1478-1484

39 Barrington SF, Qian W, Somer EJ, et al. Concordance between four European centres of PET reporting criteria designed for use in multicentre trials in Hodgkin lymphoma. Eur J Nucl Med Mol Imaging 2010;37(10):1824-1833

40 Meignan M, Gallamini A, Meignan M, Gallamini A, Haioun C. Report on the First International Workshop on interim-PET scan in lymphoma. Leuk Lymphoma 2009;50(08):1257-1260

41 Jain S, Kapoor G, Bajpai R. ABVD-based therapy for Hodgkin lymphoma in children and adolescents: lessons learnt in a tertiary care oncology center in a developing country. Pediatr Blood Cancer 2016;63(06):1024-1030

42 Radhakrishnan V, Dhanushkodi M, Ganesan TS, et al. Pediatric Hodgkin lymphoma treated at cancer institute, Chennai, India: long-term outcome. J Glob Oncol 2016;3(05):545-554

43 Chandra J, Naithani R, Singh V, Saxena YK, Sharma M, Pemde H. Developing anticancer chemotherapy services in a developing country: Hodgkin lymphoma experience. Pediatr Blood Cancer 2008;51(04):485-488

44 Laskar S, Gupta T, Vimal S, et al. Consolidation radiation after complete remission in Hodgkin's disease following six cycles of doxorubicin, bleomycin, vinblastine, and dacarbazine chemotherapy: is there a need? J Clin Oncol 2004;22(01):62-68

45 Dinand V, Arya LS. Epidemiology of childhood Hodgkins disease: is it different in developing countries? Indian Pediatr 2006;43 (02):141-147http://www.ncbi.nlm.nih.gov/pubmed/16528110 Accessed April 15, 2021
46 Hoppe RT, Advani RH, Ai WZ, et al. Hodgkin lymphoma version 1.2017, NCCN clinical practice guidelines in oncology. http:// www.ncbi.nlm.nih.gov/pubmed/28476741 Accessed April 15, 2021J Natl Compr Canc Netw 2017;15(05):608-638

47 Paulino AC, Margolin J, Dreyer Z, Teh BS, Chiang S. Impact of PET$\mathrm{CT}$ on involved field radiotherapy design for pediatric Hodgkin lymphoma. Pediatr Blood Cancer 2012;58(06):860-864

48 Miller E, Metser U, Avrahami G, et al. Role of 18F-FDG PET/CT in staging and follow-up of lymphoma in pediatric and young adult patients. J Comput Assist Tomogr 2006;30(04): 689-694

49 Montravers F, McNamara D, Landman-Parker J, et al. [(18)F]FDG in childhood lymphoma: clinical utility and impact on management. Eur J Nucl Med Mol Imaging 2002;29(09):1155-1165

50 Depas G, De Barsy C, Jerusalem G, et al. 18F-FDG PET in children with lymphomas. Eur J Nucl Med Mol Imaging 2005;32(01): 31-38

51 Totadri S, Radhakrishnan V, Ganesan TS, et al. Can radiotherapy be omitted in children with Hodgkin lymphoma who achieve metabolic remission on interim positron emission tomography? experience of a tertiary care cancer referral center. J Glob Oncol 2018;4 (04):1-7

52 Lopci E, Burnelli R, Ambrosini V, et al. (18)F-FDG PET in Pediatric Lymphomas: a comparison with conventional imaging. Cancer Biother Radiopharm 2008;23(06):681-690

53 Levine JM, Weiner M, Kelly KM. Routine use of PET scans after completion of therapy in pediatric Hodgkin disease results in a high false positive rate. J Pediatr Hematol Oncol 2006;28(11): 711-714 